\title{
Current perspectives on cardioembolic ischemic stroke in very old patients
}

This article was published in the following Dove Press journal:

Research Reports in Clinical Cardiology

22 December 2014

Number of times this article has been viewed

\section{Adrià Arboix' \\ Joan Massons' \\ Josefina Alió ${ }^{2}$}

'Division of Cerebrovascular Diseases, Department of Neurology, Hospital Universitari del Sagrat Cor, University of Barcelona, ${ }^{2}$ Department of Cardiology, Hospital Universitari de Bellvitge, L'Hospitalet de Llobregat, Barcelona, Catalonia, Spain

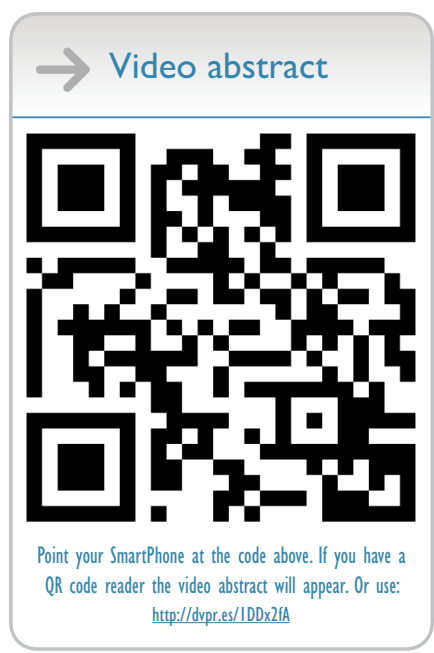

Correspondence: Adrià Arboix Division of Cerebrovascular Diseases, Department of Neurology, Hospital Universitari del Sagrat

Cor, C/Viladomat 288,

E-08029 Barcelona, Catalonia, Spain

Tel +34934948940

Fax+34934948906

Email aarboix@hscor.com
Abstract: The oldest old population ( $>85$ years of age) represents the faster growing segment of the elderly in developed countries. Cardioembolic infarction (CI) accounts for $14 \%-30 \%$ of all cerebral infarcts and is the most severe ischemic stroke subtype with the highest in-hospital mortality. Also, CI is associated with a low frequency of symptom-free patients at hospital discharge and presents a non-negligible risk of early embolic recurrence. Moreover, cardioembolic stroke is the acute cerebrovascular event most commonly found in very old subjects. However, some clinical aspects of the natural course of the disease in very old patients are still poorly defined. The present report presents an updated review of relevant aspects of CI related to clinical manifestations, biological characteristics, prognostic implications, and treatment strategies, which may contribute to improving the quality of care and outcome of acute cardioembolic stroke in very old patients. The most relevant aspects of CI are discussed based on the data published in the literature and the authors' experience in the management of stroke patients, collected from the hospital-based "Sagrat Cor Hospital of Barcelona Stroke Registry". The following aspects are commented on: epidemiologic data and risk factors, clinical characteristics, cardiac workup studies, special cardioembolic clinical features, outcome, thrombolytic therapy, antithrombotic treatment, and indications for future research lines. Cardioembolic stroke is an important topic in the frontier between cardiology and vascular neurology. The impact of CI on the patients' health and quality of life, health care systems, and society in general merits an in-depth review of current clinical issues, advances, and controversies.

Keywords: cardioembolic infarction, epidemiology, risk factors, secular trends, stroke registry, very old patients

\section{Introduction}

The importance of studies on acute cerebrovascular events in older stroke victims is growing because of the changes in the age structure of Western populations. ${ }^{1-3}$ The oldest old ( 85 years or older) represents the faster growing segment of the elderly in developed countries. ${ }^{4}$ In very old patients, cardioembolic stroke is the ischemic stroke subtype that occurs more frequently. ${ }^{5}$ Although there are no absolute criteria for the diagnosis of cardioembolic infarction $(\mathrm{CI})$, the following characteristics are required: 1) compatible neurovascular clinical picture, 2) recognition of an emboligenous heart disease, and 3 ) exclusion of carotid and/or cerebral atherosclerosis as main causes of ischemic stroke. ${ }^{6,7}$

There are few studies on acute ischemic stroke in very old subjects, and little information has been published in relation to the cardiovascular risk factors profile for $\mathrm{CI}$ in this age group. ${ }^{8}$ Ischemic stroke causes considerable disability, a need for rehabilitation submit your manuscript $\mid$ www.dovepress.com

Dovepress

http://dx.doi.org/10.2147/RRCC.S45809
Research Reports in Clinical Cardiology 2015:6 I-10

(c) (i) (5) 2015 Arboix et al. This work is published by Dove Medical Press Limited, and licensed under Creative Commons Attribution - Non Commercial (unported, v3.0) License. The full terms of the License are available at http://creativecommons.org/licenses/by-nc/3.0/. Non-commercial uses of the work are permitted without any further permission from Dove Medical Press Limited, provided the work is properly attributed. Permissions beyond the scope of the License are administered by Dove Medical Press Limited. Information on how to request permission may be found at: http://www.dovepress.com/permissions.php 
and support, and a high economic burden. Currently, one third of all the patients with first-ever acute ischemic stroke are $>85$ years old. ${ }^{2,3,9}$ As life expectancy continues to rise, elderly subjects eventually will constitute the majority of stroke victims. ${ }^{4}$ Acute ischemic stroke in very old patients is rapidly becoming a major public health issue. In addition, it has been shown that older stroke patients are particularly at risk of receiving suboptimal care, with brain neuroimaging studies and other diagnostic tools used less frequently than in younger patients. ${ }^{10}$ Additionally, sufficient rehabilitation time for older fragile comorbid stroke patients to help their recovery is still an unmet need in many rehabilitation wards and nursing homes.

In the oldest old population, age 85 and over is an arbitrary cutoff age limit for exclusion of stroke patients from clinical trials. Elderly patients are often excluded from clinical trials studying recombinant tissue plasminogen activator (rtPA) or anticoagulation in presumed cardioembolic ischemic stroke. Studies that have focused on very old patients suggest that very old stroke patients have higher in-hospital mortality rates, longer lengths of hospital stay, and receive lesser aggressive care than younger patients. ${ }^{10-14}$ Because of all these considerations, diagnosis and management of CI continue to be a current challenge for physicians, nurses, physical therapists, policy makers, and the society in general.

\section{Clinical characteristics}

Cardioembolic cerebral infarction accounts for $18 \%-25 \%$ of all cerebral infarctions ${ }^{15-17}$ and is the ischemic stroke subtype most commonly found in very old patients ( $>85$ years of age) ${ }^{5,18}$ In 2,990 patients included in the "Sagrat Cor Hospital of Barcelona Stroke Registry" between 1986 and 2004, CI in very old patients (mean age 88.5 years) accounted for $28.4 \%$ of first-ever strokes followed by atherothrombotic infarcts (21\%) and lacunar infarctions (14.2\%), whereas in patients younger than 85 years (mean age 70.9 years), lacunar infarction $(20.1 \%)$ and atherothrombotic infarcts (18.4\%) were more frequent than CI $(17.5 \%)$. This may be explained by the fact that the most common emboligenous cardiopathy atrial fibrillation - is more prevalent in the subgroup of very old ischemic stroke patients (43.2\%) as compared with other age subgroups (34.3\% in the 75-84-year age group, $23.1 \%$ in the 65-74-year age group, and $9.8 \%$ in the $<65$-year age group). ${ }^{19,20}$ It should be noted that in the oldest old patients, atrial fibrillation is the second vascular risk factor after hypertension, which is in contrast to ages $<65$ years and 65-74 years, during which hypertension, diabetes mellitus, and dyslipidemia are the most common risk factors. ${ }^{20}$
Cardioembolic stroke is a severe condition due to the large size of the infarction, with a high in-hospital mortality rate $(6 \%-27 \%)$ and significant neurological dysfunction; also, the risk of spontaneous infarct recurrence ranges between $1 \%$ and $10 \% .{ }^{21-23}$ Histopathological examination of the lesion area usually reveals a hemorrhagic cerebral infarction (Figure 1).

Salient clinical manifestations of CI (Table 1) include sudden onset of neurological deficit, maximum focal neurological dysfunction at the onset of clinical symptoms, stroke onset while awake, speech disturbances, and the presence of a non-lacunar clinical syndrome. ${ }^{24}$ Early differential diagnosis of CI should be mainly established with atherothrombotic infarctions, and sometimes, this differential diagnosis can be difficult on the basis of clinical symptoms alone. ${ }^{20}$ However, in a comparative clinical study, it was found that sudden onset of neurological deficit and heart rhythm disturbance were independent predictive variables of cardioembolism, whereas hypertension, diabetes, dyslipidemia, and chronic obstructive pulmonary disease (COPD) were significantly related to atherothrombotic infarction. ${ }^{20}$ Also, atrial fibrillation, heart valve disease, and ischemic heart disease are characteristic cardiovascular risk factors for CI, in contrast

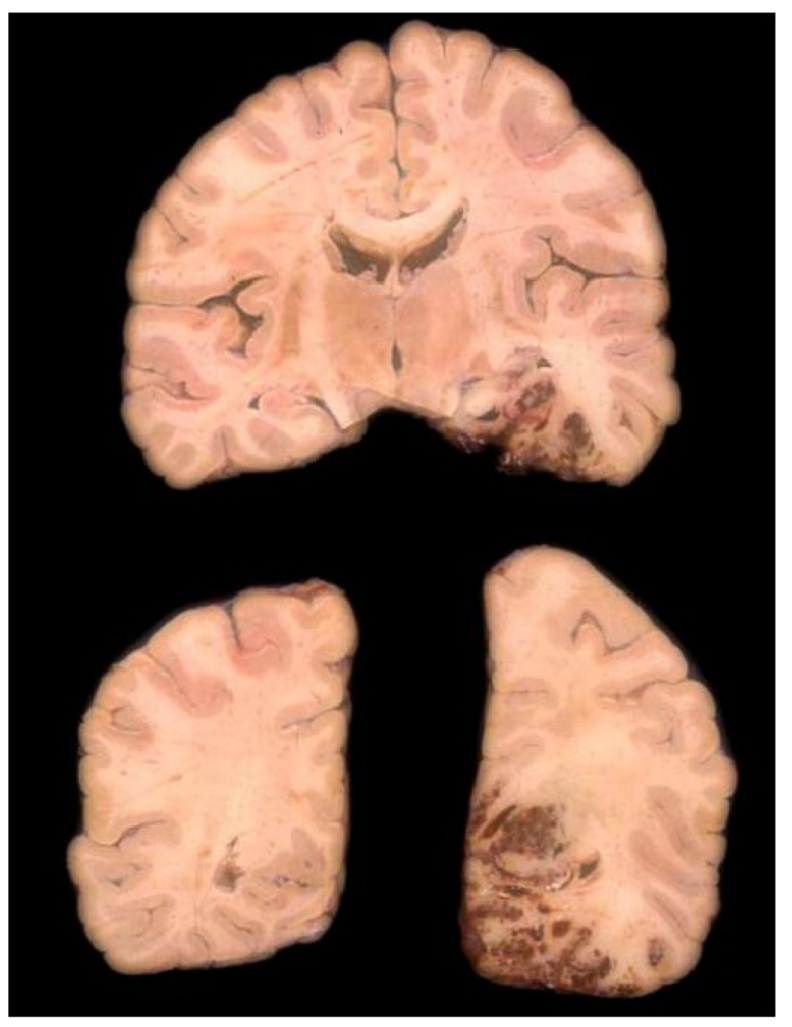

Figure I Pathological specimen showing a hemorrhagic cerebral infarction of cardioembolic origin in the vascular superficial distribution territory of the posterior cerebral artery. 
Table I Clinical characteristics of cardioembolic infarction

Sudden onset of focal neurological deficit

Maximum focal neurological dysfunction at onset of clinical symptoms Stroke onset while awake

Onset after a Valsalva maneuver (paradoxical embolism)

Presence of a non-lacunar clinical syndrome

Wernicke aphasia

Isolated aphasia

Spectacular shrinking deficit syndrome

Concomitant peripheral vascular embolism

Simultaneous cerebral infarcts in different territories on neuroimaging studies

to the profile of atherothrombotic stroke characterized by the presence of peripheral vascular disease, diabetes, previous transient ischemic attack or cerebral ischemia, as well as concomitant ischemic heart disease. ${ }^{20,25}$

The commonest high-risk cardioembolic conditions are atrial fibrillation, recent myocardial infarction, mechanical prosthetic valve, dilated myocardiopathy, and mitral rheumatic stenosis. ${ }^{26-28}$ Other types of heart diseases associated with a high risk of embolism are atrial or ventricular thrombi, atrial myxoma and cardiac tumors, infectious/ marantic endocarditis, complex aortic arch atheroma, and dilated myocardiopathy with ventricular ejection fraction $<35 \%{ }^{29}$

\section{Diagnostic studies}

In the last decade, the diagnosis of CI was mainly a "presumed" diagnosis based on clinical features and electrocardiography findings. However, clinical diagnosis of CI has recently shown a substantial advance in relation to the use of echocardiography in routine clinical practice, 24-hour Holter monitoring, and diffusion magnetic resonance imaging, allowing a noninvasive diagnosis of potentially emboligenous structural heart diseases, detection of clinically silent paroxysmal heart rhythm disorders, or acute multiple simultaneous cerebral infarctions, which are characteristics of the embolic phenomena. ${ }^{30-32}$ Also, recent development of biological markers related to cerebral cardioembolism, such as high serum levels of brain natriuretic peptide of D-dimer, is useful to increase the sensitivity of the diagnosis of embolic etiology of the brain infarction in those cases of cerebral ischemia of undetermined or mixed etiology. ${ }^{33,34}$

In a comparative study of 575 patients with CI, collected from the "Sagrat Cor Hospital of Barcelona Stroke Registry" over a period of 19 years, the percentage of patients in whom echocardiography was used increased from $39.7 \%$ in $1986-1992$ to $66.9 \%$ in $1993-1998$ and $73.9 \%$ in 1999-2004. ${ }^{18}$ The use of echocardiography also increased notably in very old patients (16\% in 1986-1992, $27.3 \%$ in $1993-1998,38.2 \%$ in 1999-2004).

\section{Outcome Early mortality}

Cardioembolic stroke is the subtype of cerebral infarction with the highest in-hospital mortality. ${ }^{1,35,36}$ In our experience, early mortality rate due to CI prior to the use of thrombolytic therapy was $21.9 \%$, similar to that reported by Caplan et al, ${ }^{37}$ as compared to $8.2 \%$ in the remaining non-cardioembolic strokes, with a frequency of $0.8 \%$ in lacunar infarcts and $21.7 \%$ in atherothrombotic stroke. ${ }^{38}$

In patients with cerebral infarction, in-hospital mortality rates were $30 \%, 22 \%$, and $18 \%$ for patients with congestive heart failure, atrial fibrillation, and COPD, respectively. In the subgroup of cardioembolic stroke, risk factors independently related with in-hospital death were peripheral vascular disease, previous cerebral infarction, and congestive heart failure. In a stepwise multivariate analysis, in which demographic variables, cardiovascular risk factors, clinical features, and neuroimaging findings were included, decreased consciousness, limb weakness, congestive heart failure, male sex, and age were statistically significant variables independently associated with cardioembolic stroke. Age was an independent factor associated with in-hospital mortality. In addition to these variables, early recurrent embolism was also selected. ${ }^{38}$

Age is an independent predictive factor associated with in-hospital mortality in stroke patients. ${ }^{1,2}$ In a comparison between patients aged $\geq 85$ years and those aged $<85$ years, advanced age was a predictive factor for early mortality in patients with stroke in general ( $27 \%$ vs $13.5 \%) .{ }^{19}$ In patients with CI, in-hospital death is also more frequent in very old patients $(25 \%$ vs $11.5 \%) .{ }^{38}$

A summary of demographic variables, cerebrovascular risk factors, neuroimaging findings, and outcome of firstever stroke patients according to age ( $\leq 84$ vs $\geq 85$ years), collected from the "Sagrat Cor Hospital of Barcelona Stroke Registry" for the period 1986-2004, is shown in Table 2.

\section{Cardioembolic recurrence}

The risk of early stroke recurrence in cerebral infarcts ranges between $1 \%$ and $10 \%$. In the Cerebral Embolism Task Force, it was estimated that $12 \%$ of patients with cardioembolic stroke would develop a second embolism within the first 2 weeks after the initial event. ${ }^{39}$ In our experience, early embolic recurrence was documented in 24 out of 347 consecutive patients with $\mathrm{CI}(6.9 \%$ of cases $) .{ }^{40}$ Recurrence 
Table 2 Demographic variables, cerebrovascular risk factors, neuroimaging findings, and outcome in the first-ever stroke according to age ("Sagrat Cor Hospital of Barcelona Stroke Registry" for the period 1986-2004)

\begin{tabular}{|c|c|c|c|}
\hline \multirow[t]{2}{*}{ Variables } & \multicolumn{2}{|c|}{ Age of the patients } & \multirow[t]{2}{*}{$P$-value } \\
\hline & $\begin{array}{l}\geq 85 \text { years } \\
(n=577)\end{array}$ & $\begin{array}{l}\leq 84 \text { years } \\
(n=2,4 \mid 3)\end{array}$ & \\
\hline Age (years), mean (SD) & $88.55(3.2)$ & $70.95(11.1)$ & 0.0000 \\
\hline Sex & & & 0.0000 \\
\hline Males & $180(3 \mid .2)$ & $\mathrm{I}, 267(52.5)$ & \\
\hline Females & $397(68.8)$ & $\mathrm{I}, \mathrm{I} 46(47.5)$ & \\
\hline Hypertension & $293(50.8)$ & $1.344(55.7)$ & 0.033 \\
\hline Diabetes & $88(15.3)$ & $3,537(22.3)$ & 0.000 \\
\hline Atrial fibrillation & $212(36.7)$ & $543(22.5)$ & 0.000 \\
\hline Ischemic heart disease & $76(13.2)$ & $341(14.1)$ & 0.500 \\
\hline Heart failure & $60(10.4)$ & $71(2.9)$ & 0.000 \\
\hline Heart valve disease & $29(5.0)$ & $146(6.1)$ & 0.346 \\
\hline TIA & $63(10.9)$ & $282(11.7)$ & 0.604 \\
\hline Chronic bronchitis & $55(9.5)$ & $177(7.3)$ & 0.076 \\
\hline Peripheral vascular disease & $29(5.0)$ & $184(7.6)$ & 0.029 \\
\hline $\begin{array}{l}\text { Heavy smoking } \\
\text { (>20 cigarettes/day) }\end{array}$ & $8(1.4)$ & $292(12.1)$ & 0.000 \\
\hline Dyslipidemia & $65(11.3)$ & $498(20.6)$ & 0.000 \\
\hline Headache & $48(8.3)$ & $415(17.2)$ & 0.000 \\
\hline Nausea, vomiting & $4 I(7.1)$ & $246(10.2)$ & 0.024 \\
\hline Altered consciousness & $165(28.6)$ & $364(15.1)$ & 0.000 \\
\hline Motor impairment & $444(76.9)$ & I,658 (68.7) & 0.000 \\
\hline Speech disturbance & $32 I(55.6)$ & I, I $85(49.1)$ & 0.005 \\
\hline Stroke subtypes & & & 0.000 \\
\hline TIA & $79(13.7)$ & $423(17.5)$ & \\
\hline Atherothrombotic & $|2|(2 \mid .0)$ & $444(18.4)$ & \\
\hline Lacunar & $82(14.2)$ & $484(20.1)$ & \\
\hline Cardioembolic & $164(28.4)$ & $4 I I(17.0)$ & \\
\hline Unknown cause & $53(9.2)$ & $227(9.4)$ & \\
\hline Infrequent etiology & $4(0.7)$ & $92(3.8)$ & \\
\hline Intracerebral hemorrhage & $58(10.1)$ & $276(11.4)$ & \\
\hline Subarachnoid hemorrhage & $5(0.9)$ & $38(1.6)$ & \\
\hline Subdural hematoma & II (I.9) & $17(0.7)$ & \\
\hline Epidural hematoma & 0 & $\mathrm{I}(0.0)$ & \\
\hline $\begin{array}{l}\text { Middle cerebral artery } \\
\text { topography }\end{array}$ & $266(46.1)$ & $\mathrm{I}, 004(4 \mathrm{I} .6)$ & 0.05 \\
\hline Echocardiography & $250(43.3)$ & $\mathrm{I}, 030(42.7)$ & 0.779 \\
\hline MRI & $72(12.5)$ & $756(31.3)$ & 0.000 \\
\hline Neurologic complications & $74(12.5)$ & $236(9.8)$ & 0.031 \\
\hline Respiratory complications & $86(14.9)$ & $150(6.2)$ & 0.009 \\
\hline Urinary complications & $68(11.8)$ & $159(6.6)$ & 0.000 \\
\hline Infectious complications & $114(19.8)$ & $24 I(10.1)$ & 0.000 \\
\hline Symptom-free at discharge & $154(26.7)$ & $951(39.4)$ & 0.000 \\
\hline In-hospital death & $126(21.8)$ & $225(9.3)$ & 0.000 \\
\hline $\begin{array}{l}\text { Transfer to convalescent/ } \\
\text { rehabilitation units }\end{array}$ & $78(\mid 3.5)$ & $238(9.9)$ & 0.010 \\
\hline $\begin{array}{l}\text { Length of stay (days), } \\
\text { median (interquartile range) }\end{array}$ & $12(8-20)$ & II (7-19) & 0.184 \\
\hline $\begin{array}{l}\text { Prolonged hospital stay } \\
>12 \text { days }\end{array}$ & $266(46.1)$ & $\mathrm{I}, 030(42.7)$ & 0.137 \\
\hline
\end{tabular}

Note: Data are expressed as numbers and percentages in parentheses unless otherwise stated.

Abbreviations: SD, standard deviation; TIA, transient ischemic attack; MRI, magnetic resonance imaging. occurred within the first 7 days in 12 patients $(50 \%)$. The mean time for recurrence of cardioembolism was 12 days. In other studies, cardioembolic recurrence at 30 days was observed in five $(6.1 \%)$ out of 81 patients with $\mathrm{CI}$ and nonvalvular atrial fibrillation in the study of Yamanouchi et $\mathrm{al},{ }^{41}$ in $6 \%$ of patients with cerebral infarctions in the study of Sacco et al, ${ }^{42}$ in 3.3\% in the Stroke Data Bank, ${ }^{43}$ and in $4.4 \%$ in the Lausanne Stroke Registry. ${ }^{44}$

Risk factors for stroke recurrence are poorly known. In our experience, alcohol abuse, hypertension with valve heart disease and atrial fibrillation, nausea and vomiting, and previous cerebral infarction were significantly associated with stroke recurrence. ${ }^{40}$ In addition to these four variables, cardiac events (tachyarrhythmia, heart failure, or acute myocardial infarction that occurred as medical complication during the patient's hospital stay) were selected in the multivariate model based on clinical, neuroimaging, and outcome variables. ${ }^{40}$ However, neither age nor advanced age was per se an independent risk factor for cardioembolic recurrence.

\section{Atrial fibrillation as a prognostic factor in cardioembolic and atherothrombotic infarcts}

Atrial fibrillation is the most common heart disease in different clinical series of patients with CI in industrialized countries. ${ }^{45-48}$ Atrial fibrillation can also be present in atherothrombotic infarctions, not as an emboligenous etiology but as a marker of other conditions that lead to ischemic stroke, such as atherosclerosis. Accordingly, it may be considered as an epiphenomenon or another manifestation of atherosclerotic disease. Therefore, not all cases of cerebral infarctions in patients with atrial fibrillation have a cardioembolic origin. ${ }^{49}$ In a study of our group, atrial fibrillation was diagnosed in $16.5 \%$ of patients with thrombotic occlusion or arterial stenosis $>70 \%$, which were presumably responsible for the cerebral infarct. ${ }^{20}$

In patients with CI, in-hospital mortality rate was $31.6 \%$ in patients with atrial fibrillation and $14.8 \%$ in those without atrial fibrillation. Moreover, in-hospital mortality in patients with atherothrombotic infarction was significantly higher in the atrial fibrillation group (29.3\%) than in the non-atrial fibrillation group (18.8\%). ${ }^{20}$ Of note, that atrial fibrillation was associated with a poorer prognosis both in CI and atherothrombotic stroke as compared with stroke patients without atrial fibrillation, probably because patients with CI showed a higher frequency of congestive heart failure and patients with atherothrombotic infarct, a higher rate of ischemic heart disease. Chronic atrial fibrillation may cause 
a significant reduction in cerebral regional blood flow, ${ }^{50,51}$ which can be normalized by establishment of sinus rhythm after successful cardioversion.

Also, an increase in mortality in CI with atrial fibrillation may be explained by the more advanced age of the patients, greater size of cerebral infarction, or higher neurological deficit at stroke onset. ${ }^{52}$ In a study of our group ${ }^{20}$ the mean age of patients with $\mathrm{CI}$ and atrial fibrillation was 77.9 years vs 72.3 years in those without atrial fibrillation. In the group of patients with atherothrombotic stroke, mean ages were 77.4 years in the atrial fibrillation group and 74.9 years in the non-atrial fibrillation group. In all cases, differences were statistically significant. ${ }^{20}$

\section{Special situations \\ Cardioembolic lacunar stroke}

In about $80 \%-95 \%$ of cases, symptomatic lacunar strokes are caused by microatheromatosis in the proximal segment of a penetrating arteriole or by an intracranial branch atheromatous disease. ${ }^{53,54}$ In contrast, most clinically asymptomatic or silent lacunes detected on neuroimaging studies are caused by lipohyalinosis of the smallest penetrating arterioles. In the remaining $5 \%-20 \%$ of cases, lacunar strokes may be due to other etiologies with embolism (of cardiac origin or from a complex atheromatosis of the aortic arch) as one of the most prevalent of the infrequent causes. ${ }^{55-57}$

In a clinical series of patients with lacunar infarction, it was found that emboligenous cardiopathy as the only cause was present in a very small percentage of patients $(4 \%) .^{58}$ However, the cardioembolic pathogenetic mechanism may be more frequent than apparently expected in very old patients ( $\geq 85$ years) in whom atrial fibrillation occurs in $28.2 \%$ of cases vs $8.7 \%$ of patients under 85 years old, and has been independently associated with cardioembolic lacunar stroke. ${ }^{5}$ Hypertension (61.5\% vs $77.3 \%$ ) and diabetes mellitus $(7.7 \%$ vs $28.4 \%)$ were less frequent in very old patients with cardioembolic lacunar stroke. In the very elderly, the higher occurrence of atrial fibrillation, the lower prevalence of hypertension and diabetes, and the greater focal neurological impairment (the absence of neurological deficit at discharge, $15.4 \%$ vs $35.2 \%$ in patients $<85$ years) suggest that the cardioembolic mechanism may be more frequent than generally established for lacunar infarcts in stroke patients.

In another study, ${ }^{59}$ diffusion-weighted imaging (DWI) was normal in nine out of the 62 patients (14.5\%) admitted with a classical lacunar syndrome. Forty-two patients $(67.7 \%)$ had a single hyperintense lesion in the territory of deep hemispheric or brain stem penetrators. DWI showed multiple regions of increased signal intensity in $16 \%$ of patients in either a single (six patients) or different (four patients) vascular territories, strongly indicating an emboligenous stroke mechanism.

Lacunar infarction due to embolism from the aortic arch that occurred in two patients with pure motor hemiplegia during cardiac and arch angiography has been reported.$^{60}$ In a recent study, the possible embolic etiology due to complex atheromatosis of the aortic arch was observed in 3\% of 71 patients with lacunar infarction. ${ }^{61}$ Two patients in this study were 87 years and 91 years old; the first patient presented a lacunar infarction in the internal capsule causing pure motor hemiparesis, and the second patient had a capsule-ganglionar lacunar infarction causing a sensorimotor syndrome. In the study of Kazui et al, ${ }^{62}$ aortic arch atheroma was independently associated with an increased risk of lacunar stroke. The finding of multiple acute infarcts by DWI in different vascular territories strongly indicates embolism. ${ }^{63-66}$

\section{Complex atheromatosis of the aortic arch}

Ultrasonography of the aortic arch allows optimizing the diagnosis of complex atheromatosis of the aortic arch, which is an emerging etiology of primary or recurrent cerebral ischemia, particularly in the subgroup of patients with cerebral infarction of unknown cause.$^{67-69}$ The main criteria of the emboligenic risk of aortic plaques include a plaque thickness equal to or greater than $4 \mathrm{~mm}$ and the presence of mobile components inside the plaque..$^{70,71}$

The association of complex atheromatosis of the aortic arch with mitral annular calcification is another interesting observation. Mitral annular calcification has been traditionally considered a cerebrovascular risk factor, despite the fact that calcium embolism is an exceptional cause of stroke. It may be argued that mitral valve ring calcification is an epiphenomenon and a marker of complex atheromatosis of the aortic arch, with its high emboligenous risk due precisely to this association. ${ }^{72}$ In a clinical series of 121 patients with cerebral infarction of undetermined cause, dense mitral annular calcification was observed in $58.3 \%$ of patients with complex atheromatosis of the aortic arch as compared with $16.3 \%$ of patients without complex atheromatosis of the aortic arch. Plaques with mobile component (grade III) were found in $28 \%$ and $9 \%$ of patients with and without complex atheromatosis of the aortic arch, respectively. Finally, patients with complex atheromatosis of the aortic arch in two or more of the three zones (ascending aorta, aortic arch, and thoracic descending aorta) showed dense mitral annular calcification more frequently than those with aortic arch atheromatosis in a 
single area ( $46 \%$ vs $9 \%$ ). The mean age of patients with dense mitral annular calcification was 70.6 years as compared to a mean age of 70.5 years for patients without mitral annular calcification. Data referring to this clinical situation in very old patients are not available.

\section{Paroxysmal atrial fibrillation}

The indication of a 24-hour (or longer) Holter monitoring and also, in selected cases, transtelephonic monitoring or subcutaneous implantation to obtain a prolonged duration of cardiac rhythm monitorization allowed to increase the diagnosis of rhythm disturbances with a high emboligenous risk, such as paroxysmal atrial fibrillation or sinus node disease. ${ }^{73-75}$

The routine use of transcranial Doppler ultrasound has also contributed to improving the diagnosis of right-to-left shunt through a patent foramen ovale when bubble signs are detected in the middle cerebral artery after injection of agitated saline via the antecubital vein. ${ }^{76,77}$

Both Holter monitoring and transcranial Doppler ultrasound are noninvasive diagnostic procedures and can be safely performed in the oldest old.

\section{Thrombolytic therapy}

At the present time and from the perspective of routine daily practice, the indication of vascular repermeabilization with the use of intravenous thrombolysis with rt-PA during the first $41 / 2$ window hours in the acute phase of CI is well established. Recommended total dose is $0.9 \mathrm{mg} / \mathrm{kg}$ infused over 60 minutes (loaded with $10 \%$ of the dose). Treatment with rt-PA should be administered to patients aged 18 years or more, in the presence of a significant neurological deficit, computed tomography evidence of the absence of intracerebral hemorrhage, or extensive cerebral infarction (greater than one third of middle cerebral artery territory), and in patients without contraindications for thrombolytic therapy. Treatment with rt-PA should be prescribed by staff neurologists and should be administered in hospitals, in which patients can be controlled adequately (it is recommended to treat patients with intravenous rt-PA in a stroke unit). ${ }^{78-80}$ However, telemedicine for stroke may be a potential solution and may maximize the number of patients given effective acute stroke treatment. ${ }^{81}$ Antithrombotic agents (heparin, aspirin) should not be given within 24 hours of rt-PA administration. Before thrombolytic therapy, it is recommended to reduce blood pressure (BP) if BP levels are $185 / 110 \mathrm{mmHg}$ or higher. Also, to be effective, thrombolytic therapy should be given as quickly as possible, with higher benefits during the first 90 minutes after stroke onset.
Bleeding is the greatest risk of thrombolytic therapy, which occurs in $2.3 \%-6.4 \%$ of the patients. Very old age, hyperglycemia on admission, greater initial neurological deficit, and early signs of cerebral ischemia are predictive factors of hemorrhagic complications of intravenous thrombolysis. ${ }^{82,83}$ For this reason, clinical protocols of therapeutic indication of intravenous rt-PA should be strictly followed.

In patients with specific contraindications for intravenous thrombolytic therapy, intra-arterial thrombolysis with rt-PA by means of an angiography is a potentially beneficial treatment. Occlusion of a large artery should be present. ${ }^{84}$ In general, in patients with predisposition to hemorrhage, intra-arterial thrombolysis is even safer and recommendable than intravenous thrombolytic therapy, although mechanical thrombectomy may be another preferable alternative to intravenous thrombolysis. ${ }^{85,86}$ Intra-arterial thrombolysis is a therapeutic option in patients with acute ischemic stroke of less than 6-hours duration caused by middle cerebral artery occlusion. In young patients with acute thrombosis of the basilar artery trunk of less than 12-hours duration, intraarterial thrombolysis may be considered, given the unfavorable prognosis of this type of thrombosis. ${ }^{87}$

Mechanical thrombectomy is a promising new modality of interventional stroke treatment. Thrombectomy devices are delivered by endovascular access proximal to the occlusion site. Although the experience is limited, an advantage over pharmacological thrombolysis is that the risk of bleeding is not increased. Indications of mechanical thrombectomy are similar to those of intra-arterial thrombolysis, but this procedure is particularly recommendable in patients at high hemorrhagic risk. ${ }^{85,86,88}$

Adequate control and treatment of cerebrovascular risk factors are needed, preventing hyperglycemia and treating hyperthermia during the acute stroke phase, as well as prevention of deep vein thrombosis with low-weight heparin. In contrast, statins are not indicated in the treatment of CI. ${ }^{89}$

\section{Rescue and primary endovascular treatment}

Rescue endovascular treatment is a strategy that includes the use of intravenous thrombolysis followed by intra-arterial thrombolysis in cases with no improvement and persistence of vascular occlusion. The 6-hour window from the onset of clinical symptoms should be maintained for intra-arterial thrombolysis, 8 hours for mechanical thrombectomy in the anterior cerebral territory, and up to 12 hours in basilar artery occlusions because the cerebral territory has a better tolerance to prolonged ischemia. ${ }^{90}$ In patients with an absolute 
contraindication for intravenous thrombolysis (eg, patients receiving anticoagulation treatment or recent surgery), primary endovascular treatment may be recommended. However, endovascular treatment requires complex and sophisticated health care services and can only be performed in specialized and validated reference hospitals (tertiary care stroke centers).

\section{New anticoagulants in very old patients}

Until recently, antivitamin $\mathrm{K}$ anticoagulants (acenocoumarol, warfarin) were the only drugs available, which have shown a clear superiority to aspirin both in primary and secondary prevention of cardioembolic events. ${ }^{91,92}$ Oral anticoagulation (INR 2.0-3.0) has been recommended in cerebral ischemic infarction associated with atrial fibrillation. Treatment with oral anticoagulants is not recommended in patients with comorbidities, such as fall risk factors, poor compliance, uncontrolled epilepsy, or gastrointestinal bleeding. Advanced age by itself does not constitute a contraindication of oral anticoagulation. ${ }^{93}$

Patients with CI unrelated to atrial fibrillation should be treated with oral anticoagulants (INR 2.0-3.0) when the risk of stroke recurrence is high (eg, mechanical prostheses, rheumatic heart disease, myocardial infarction with left thrombus formation, left atrial enlargement, or significant left ventricular dysfunction). ${ }^{94,95}$ A combination of a lowdose aspirin and dipyridamole is recommended when oral anticoagulation is contraindicated.

In contrast, oral anticoagulation is routinely recommended in non-CI stroke except in special circumstances such as grade III complex atheromatosis of the aortic arch, fusiform aneurysms of the basilar artery, central venous thrombosis, or CI patients of undetermined cause with a patent foramen ovale in the presence of proved deep vein thrombosis or associated with atrial septal aneurysm. ${ }^{94,95}$ Also, oral anticoagulants can be indicated in patients with CI caused by arterial dissection or CI in prothrombotic stages secondary to deficiency of protein S, protein $\mathrm{C}$, and antithrombin III, lupus anticoagulant deficiency, or resistance to activated protein $\mathrm{C}$.

At the present time, three new oral anticoagulants have consistently shown a higher safety profile (dabigatran, rivaroxaban, and apixaban) and a non-inferior (rivaroxaban) or superior (dabigatran $150 \mathrm{mg}$ and apixaban) efficacy as compared to coumarin for preventing cardioembolic events in patients with non-valvular atrial fibrillation. As an additional advantage, these drugs do not need anticoagulant monitor- ization avoiding periodic hematological controls that are indispensable in patients currently treated with antivitamin $\mathrm{K}$ anticoagulants. ${ }^{96}$ The pharmacological characteristics of these drugs are shown in Table 3.

According to the current recommendations, dabigatran, rivaroxaban, and apixaban may be preferred over antivitamin $\mathrm{K}$ anticoagulants in cerebral ischemic infarction associated with non-valvular atrial fibrillation. Clinical decisions should consider risks and benefits of each drug according to individual characteristics, including history of previous diseases, risk of bleeding, patient's compliance, and patient's preferences. ${ }^{97,98}$ The experience of the use of these novel anticoagulant drugs in very old patients is scarce, but the lack of need for periodic monitoring makes these agents potentially interesting and of priority use in patients of advanced age.

\section{Future research lines}

The evidence that neurogenesis and angiogenesis play a role at cerebral level favoring brain neuroplasticity, ${ }^{99}$ and that they are stimulated by movements and exercise of the affected hemibody, supports the necessity to maintain an active and

Table 3 Pharmacological characteristics of new anticoagulant drugs

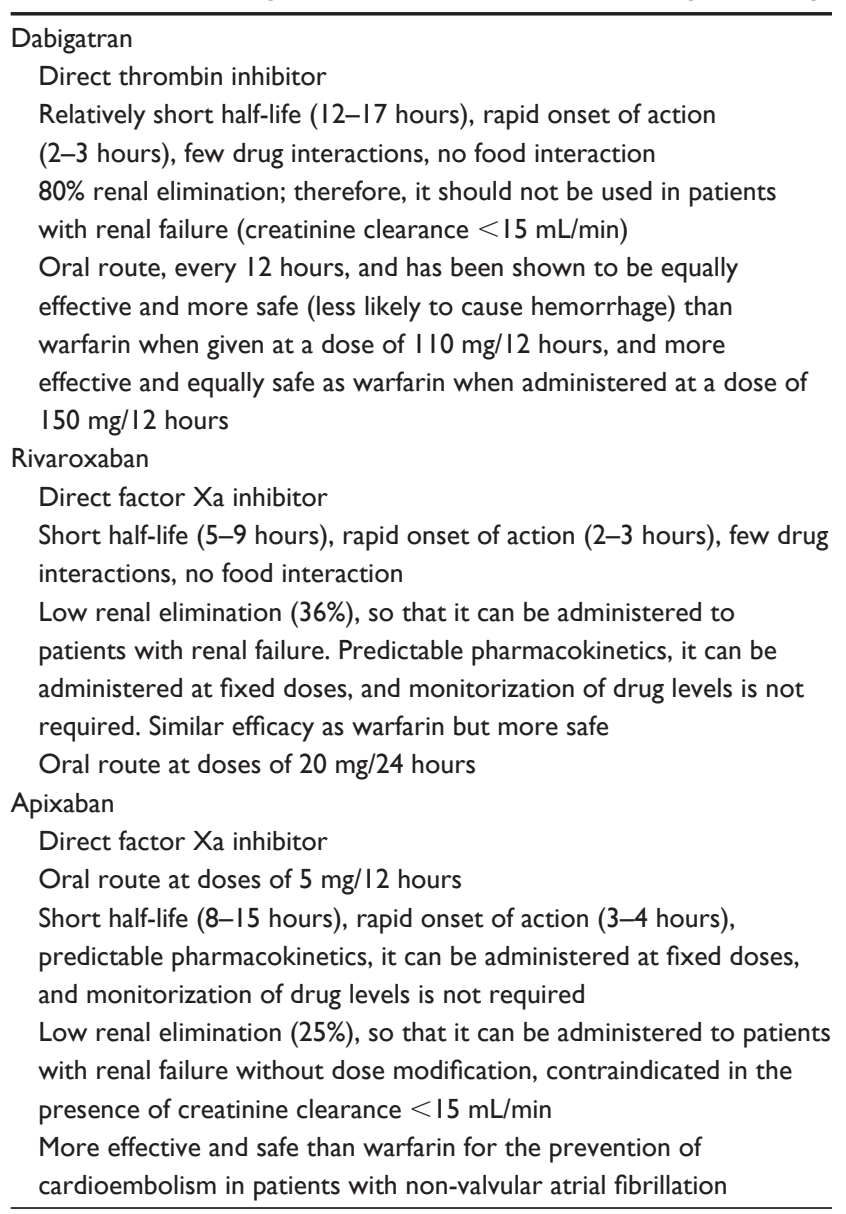


persistent attitude regarding physiotherapy and motor rehabilitation, as an indispensable therapeutic approach to improve neurological sequelae in cardioembolic stroke patients.

Some clinical research lines remain open, such as genetic-related risk of cardioembolism and recurrence, ${ }^{100-103}$ diagnosis of embolism based on biomarkers for cases of cerebral infarctions of undetermined or unknown etiology, and consolidation in daily practice of new oral anticoagulants as a more effective, safe, and comfortable therapy.

\section{Acknowledgments}

We are grateful to Maria Pizarro, Sandra Estevez, Susana Fontana, and Rosana Rouco for valuable help in the collection of data from the stroke registry, Montserrat Oliveres, Emili Comes, and Maria José Vidal for the care of many of the patients included in the study, and Marta Pulido for editing the manuscript and editorial assistance.

\section{Disclosure}

The authors report no conflicts of interest in this work.

\section{References}

1. Russo T, Felzani G, Marini C. Stroke in the very old: a systematic review of studies on incidence, outcome, and resource use. J Aging Res. 2011;2011:108785.

2. Tabereaux PB, Brass LM, Concato J, Bravata DM. Hospital admissions for stroke among the very old in the USA. Neuroepidemiology. 2008;31:93-99.

3. Rojas J, Zurrú MC, Romano M, Patrucco L, Cristiano E. Acute ischemic stroke and transient ischemic attack in the very old. Risk factors and stroke subtype between patients older than 80 years and patients aged less than 80 years. Eur J Neurol. 2007;14:895-899.

4. Campio EW. The oldest old. N Engl J Med. 1994;330:1819-1820.

5. Arboix A, Miguel M, Císcar E, García-Eroles L, Massons J, Balcells M. Cardiovascular risk factors in patients aged 85 or older with ischemic stroke. Clin Neurol Neurosurg. 2006;108:638-643.

6. Arboix A, Alió J. Cardioembolic stroke: an update. Expert Rev Cardiovasc Ther. 2011;9:367-379.

7. Ferro JM. Cardioembolic stroke: an update. Lancet Neurol. 2003;2: 177-188.

8. Bhatnagar P, Sinha D, Parker RA, Guyler P, O'Brien A. Intravenous thrombolysis in acute ischaemic stroke: a systematic review and metaanalysis to aid decision making in patients over 80 years of age. $J$ Neurol Neurosurg Psychiatry. 2011;82:712-717.

9. Olindo S, Cabre P, Deschamps R, et al. Acute stroke in the very elderly. Epidemiological features, stroke subtypes, management, and outcome in Martinique, French West Indies. Stroke. 2003;34: 1593-1597.

10. Arboix A, Vall-Llosera A, García-Eroles L, Massons J, Oliveres M, Targa C. Clinical features and functional outcome of intracerebral hemorrhage in patients aged 85 and older. J Am Geriatr Soc. 2002;50: 449-454.

11. Sharma JC, Fletcher S, Vassallo M. Strokes in the elderly. Higher acute and 3-month mortality. An explanation. Cerebrovasc Dis. 1999;9: $2-9$.

12. Bhalla A, Grieve R, Tilling K, Rudd AG, Wolfe CDA. Older stroke patients in Europe: stroke care and determinants of outcome. Age Ageing. 2004;33:618-624.
13. Khoo CW, Lip GYH. Clinical outcomes of acute stroke patients with atrial fibrillation. Expert Rev Neurother. 2009; 7:371-374.

14. Weir NU. An update on cardioembolic stroke. Postgrad Med J. 2008;84:133-142.

15. Ferro JM. Brain embolism. Answers to practical questions. J Neurol. 2003;250:139-147.

16. Hornig CR, Brainin M, Mast H. Cardioembolic stroke: results from three current stroke data banks. Neuroepidemiology. 1994;13:318-323.

17. Doufekias E, Segal AZ, Kizer JR. Cardiogenic and aortogenic brain embolism. J Am Coll Cardiol. 2008;51:1049-1059.

18. Arboix A, Massons J, Garcia-Eroles L, Targa C, Parra O, Oliveres M. Trends in clinical features and early outcome in patients with acute cardieombolic stroke subtype over a 19-year period. Neurol India. 2012;60:288-293.

19. Arboix A, Garcia-Eroles L, Comes E, et al. Importance of cardiovascular risk profile for in-hospital mortality due to cerebral infarction. Rev Esp Cardiol. 2008;6:1020-1029.

20. Arboix A, Garcia-Eroles L, Massons J, Oliveres M, Pujades R, Targa C. Atrial fibrillation and stroke: clinical presentation of cardioembolic versus atherothrombotic infarction. Int J Cardiol. 2000;73: $33-42$.

21. Murtagh B, Smalling RW. Cardioembolic stroke. Curr Atherosclr Rep. 2006;8:310-316.

22. Carrera E, Maeder-Ingvar M, Rossetti AO, Devuyst G, Bogousslavsky J. Trends in risk factors, patterns and causes in hospitalized strokes over 25 years: The Lausanne Stroke Registry. Cerebrovasc Dis. 2007;24: 97-103.

23. Asplund K, Carlberg B, Sundström G. Stroke in the elderly. Observations in a population-based sample of hospitalized patients. Cerebrovasc Dis. 1992;2:152-157.

24. Arboix A, Alió J. Cardioembolic stroke: clinical features, specific cardiac disorders and prognosis. Curr Cardiol Rev. 2010;6:150-161.

25. Arboix A, Vericat MC, Pujades R, Massons J, García-Eroles L, Oliveres M. Cardioembolic infarction in The Sagrat Cor-Alianza Hospital of Barcelona Stroke Registry. Acta Neurol Scand. 1997;96: 407-412.

26. Zhang L, Harrison JK, Goldstein LB. Echocardiography for the detection of cardiac sources of embolism in patients with stroke or transient ischemic attack. J Stroke Cerebrovasc Dis. 2012;21:577-582.

27. Wolf Ph A, Abott RD, Kannel WB. Atrial fibrillation as an independent risk factor for stroke: The Framingham Study. Stroke. 1991;22:983-988.

28. The European Stroke Organization (ESO) Executive Committee and the ESO Writing Committee. ESO Guidelines for management of ischaemic stroke 2008. Cerebrovasc Dis. 2008;25:457-507.

29. Pujadas RC, Arbox A, Casañas-Muñoz R, Anguera-Ferrando N. Specific cardiac disorders in 402 consecutive patients with ischaemic cardioembolic stroke. Int J Cardiol. 2004;95:129-134.

30. Santamarina E, Penalba A, García Ustrell X, Pellisé A. Cardiac workup of ischemic stroke. Curr Cardiol Rev. 2010;6:175-183.

31. Sposato LA, Klein FR, Jauregui A, Ferrua M, Klin P, Zamora R, et al. Newly diagnosed atrial fibrilation after acute ischemic stroke and transient ischemic attack: importance of immediate and prolonged continous cardiac monitoring. J Stroke Cerebrovasc Dis. 2012;21:210-216.

32. Young KC, Benesch CG. Transesophageal ecocardiography screening in subjects with a first cerebrovascular ischemic event. J Stroke Cerebrovasc Dis. 2011;20:503-509.

33. Montaner J, Perea-Gainza M, Delgado P, et al. Etiologic diagnosis of ischemic stroke subtypes with plasma biomarkers. Stroke. 2008;39:2280-2287.

34. Foerch C, Montaner J, Furie KL, Ning MM, Lo EH. Searching for oracles? Blood biomarkers in acute stroke. Neurology. 2009;73: 393-399.

35. Arboix A, Oliveres M, Massons J, Pujades R, Garcia-Eroles L. Early differentiation of cardioembolic from atherothrombotic cerebral infarction: a multivariate analysis. Eur J Neurol 1999;6:677-683. 
36. Lodder J, Krijne-Kubat B, Broekman J. Cerebral hemorrhagic infarction at autopsy: cardiac embolic cause and the relationship to the cause of death. Stroke. 1986;17:626-629.

37. Caplan LR, Hier DB, D'Cruz I. Cerebral embolism in the Michael Reese stroke Registry. Stroke. 1984;14:530-536.

38. Arboix A, García-Eroles L, Massons J, Oliveres M. Predictive clinical factors of in-hospital mortality in 231 consecutive patients with cardioembolic cerebral infarction. Cerebrovasc Dis. 1998;8:8-13.

39. Cerebral Embolism Task Force. Cardiogenic brain embolism. Arch Neurol. 1986;43:71-84.

40. Arboix A, García Eroles L, Oliveres M, Massons JB, Targa C. Clinical predictors of early embolic recurrence in presumed cardioembolic infarction. Cerebrovasc Dis. 1988;8:345-353.

41. Yamanouchi H, Shimada H, Tomonaga M, Matsushita S. Recurrence of embolic stroke in non-valvular atrial fibrillation (NVAF). An autopsy study. Acta Neurol Scand. 1989;80:123-129.

42. Sacco RL, Shi T, Zamanillo MC, Kargman DE. Predictors of mortality and recurrence after hospitalized cerebral infarction in an urban community: The Northern Manhattan Stroke Study. Neurology. 1994;44:626-634.

43. Sacco RL, Foulkes MA, Mohr JP, Wolf PA, Hier DB, Price TR. Determinants of early recurrence of cerebral infarction. The Stroke Data Bank. Stroke. 1989;20:983-989.

44. Bogousslavsky J, Van Melle G, Regli F. The Lausanne Stroke registry: analysis of 1.000 consecutive patients with first stroke. Stroke. 1988;19:1083-1092.

45. Syme PD, Byrne AW, Chen R, Devenny R, Forbes JF. Community-based stroke incidence in a Scottish population: the Scottish Borders Stroke Study. Stroke. 2005;36:1837-1843.

46. The Paul Coverdell prototype Registries Writing Group. Acute stroke care in the US. Results from 4 pilot prototypes of The Paul Coverdell National Acute Stroke Registry. Stroke. 2005;36:1232-1240.

47. Ghandehari K, Izadi Z. The Khorasan Stroke Registry: results of fiveyear hospital-based study. Cerebrovasc Dis. 2007;23:132-139.

48. Grau AJ, Weimar C, Buggle F, et al. Risk factors, outcome, and treatment in subtypes of ischemic stroke: The German Stroke Data Bank Stroke. 2001;32:2559-2599.

49. Benbir G, Uluduz D, Ince B, Bozluolcay M. Atherothrombotic ischemic stroke in patients with atrial fibrillation. Clin Neurol Neurosurg. 2007;109:485-490.

50. Lavy S, Stern S, Melamed E, Cooper G, Keren A, Levy P. Effect of chronic atrial fibrillation on regional cerebral blood flow. Stroke. 1980;11:35-38.

51. Petersen P, Kastrup J, Videbaek R, Boysen G. Cerebral blood flow before and after cardioversion of atrial fibrillation. J Cereb Blood Flow Metab. 1989;9:422-425.

52. Friedman PJ. Atrial fibrillation after stroke in the elderly. Stroke. 1991;22:209-214.

53. Arboix A, García-Plata C, García-Eroles L, et al. Clinical study of 99 patients with pure sensory stroke. J Neurol. 2005;252:156-162.

54. Arboix A, Blanco-Rojas L, Martí-Vilalta JL. Advancements in understanding the mechanisms of symptomatic lacunar ischemic stroke: translation of knowledge to prevention strategies. Expert Rev Neurother. 2014;14:261-276.

55. Arboix A, Font A, Garro C, Comes E, Massons J. Recurrent lacunar infarction following a previous lacunar stroke: a clinical study of 122 patients. J Neurol Neurosurg Psychiatry. 2007;78:1392-1394.

56. Chamorro A, Sacco RL, Mohr JP, et al. Clinical computed tomographic correlations of lacunar infarction in the Stroke Data Bank. Stroke. 1991;22:175-181.

57. The SPS3 Investigators, Benavente OR, Hart RG, et al. Effects of clopidogrel added to aspirin in patients with recent lacunar stroke. N Engl J Med. 2012;367:817-825.

58. Arboix A, Martí-Vilalta JL. Presumed cardioembolic lacunar infarcts. Stroke. 1991;23:1841-1842.

59. Ay H, Oliveira-Filho J, Buonanno FS, et al. Diffusion-weighted imaging identifies a subset of lacunar infarction associated with embolic source. Stroke. 1999;30:2644-2650.
60. Cacciatore A, Russo LS Jr. Lacunar infarction as an embolic complication of cardiac and arch angiography. Stroke. 1991;22: 1603-1605.

61. Arboix A, Rexach M, Subirà M, Pujadas R. Complex aortic atheroma plaques: study of 71 patients with lacunar infarcts. Med Clin (Barc). 2012;138:160-164.

62. Kazui S, Levi CR, Jones EF, Quang L, Calafiore P, Donnan GA. Risk factors for lacunar stroke: a case-control transesophageal study. Neurology. 2000;5:1385-1387.

63. Wessels T, Röttger C, Jauss M, Kaps M, Traupe H, Stolz E. Identification of embolic stroke patterns by diffusion-weighted MRI n clinical defined lacunar stroke syndromes. Stroke. 2005;36:757-761.

64. Jung DK, Devuyst G, Maeder P, Bogousslavsy J. Atrial fibrillation with subcortical infarcts. J Neurol Neurosurg Psychiatry. 2001;70: 344-349.

65. Seifert T, Enzinger C, Storch MK, Pichler G, Niederkorn K, Fazekas F. Acute small subcortical infarctions on diffusion weighted MRI: clinical presentation and aetiology. J Neurol Neurosurg Psychiatry. 2005;76:1520-1524.

66. Lodder J, Bamford JM, Sandercock PAG, Jones LN, Warlow CP. Are hypertension or cardiac embolism likely causes of lacunar infarction? Stroke. 1990;21:375-381.

67. Capmany RP, Ibañez MO, Pesquer XJ. Complex atheromatous of the aortic arch in cerebral infarction. Curr Cardiol Rev. 2010;6:184-193.

68. Macleod MR, Amarenco P, Davis SM, Donnan GA. Atheroma of the aortic arch: an important and poorly recognized factor in the aetiology of stroke. Lancet Neurol. 2004;3:408-414.

69. Sharifkazemi MB, Aslani A, Zamirian M, Moaref AR. Significance of aortic atheroma in elderly patients with ischemic stroke: A hospital-based study and literature review. Clin Neurol Neurosurg. 2007;109: 311-316.

70. Jung JM, Kwon JY, Kim HJ, et al. Ischemic lesion burden and characteristics of aortic atheroma. J Stroke Cerebrovasc Dis. 2014;23: 278-282.

71. Amarenco P, Davis S, Jones EF, et al; for the Aortic Arch Related Cerebral Hazard Trial Investigators. Clopidogrel plus aspirin versus warfarin in patients with stroke and aortic arch plaques. Stroke. 2014;45:1248-1257.

72. Pujadas R, Arboix A, Anguera N, Rafel J, Sagués F, Casañas R. Mitral annular calcification as a marker of complex aortic atheroma in patients with stroke of uncertain etiology. Echocardiography. 2008;25:124-131.

73. Gaillard N, Deltour S, Vilotijevic B, et al. Detection of paroxysmal atrial fibrillation with transtelephonic EKG in TIA or stroke patients. Neurology. 2010;74:1666-1670.

74. Miller DK, Khan MA, Schultz LR, Simpson JR, Katramados AM, Russman AN, Mitsias PD. Outpatients cardiac telemetry detects a high rate of atrial fibrillation in criptogenetic stroke. J Neurol Sci. 2013;174: 57-61.

75. Wann LS, Curtis AB, January CT, et al. 2011 ACCF/AHA/HRS focused update on the management of patients with atrial fibrillation (updating the 2006 guideline): a report of the American College of Cardiology Foundation/American Heart Association Task Force on Practice Guidelines. Circulation. 2011;123:104-123.

76. Ustrell X, Pellisé A. Cardiac workup of ischemic stroke. Curr Cardiol Rev. 2010;6:175-183.

77. Serena J, Marti-Fàbregas J, Santamarina E, et al. Recurrent stroke and massive right-to-left shunt: results from the prospective Spanish multicenter (CODICIA) study. Stroke. 2008;39:3131-3136.

78. National Institute of Neurological Disorders and Stroke rt-PA Stroke Study Group. Tissue plasminogen activator for acute ischemic stroke. N Engl J Med. 1995;333:1581-1587.

79. IST-3 Collaborative Group, Sandercock P, Wardlaw JM, Lindley RI, et al. The benefits and harms of intravenous thrombolysis with recombinant tissue plasminogen activator within $6 \mathrm{~h}$ of acute ischaemic stroke (the third international stroke trial [IST-3]): a randomised controlled trial. Lancet. 2012;379:2352-2363.

80. Jauch EC, Saver JL, Adams HP Jr, et al. Guidelines for the early management of patients with acute ischemic stroke: a guideline for healthcare professionals from the American Heart Association/American Stroke Association. Stroke. 2013;44(3):870-947. 
81. Levine SR, Gorman M. "Telestroke". The application of telemedicine for stroke. Stroke. 1999;30:464-469.

82. Wahlgren N, Ahmed N, Davalos A, et al. Thrombolysis with alteplase for acute ischaemic stroke in the Safe Implementation of Thrombolysis in Stroke-Monitoring Study (SITS-MOST): an observational study. Lancet. 2007;369:275-282.

83. Hacke W, Kaste M, Fieschi C, Von Kummer R, Davalos A, Meier D, et al. Randomised double-blind placebo controlled trial of thrombolytic therapy with intravenous alteplase in acute ischaemic stroke (ECASS II). Second European-Asutralasian Acute Stroke Study Investigators. Lancet. 1998;325:1245-1251.

84. Furlan A, Higashida R, Wechsler L, et al. Intra-arterial prourokinase for acute ischemic stroke. The PROACT II study: a randomized controlled trial. Prolyse in acute cerebral thromboembolism. JAMA. 1999;282:2003-2011.

85. Smith WS, Sung G, Saver J, et al. Mechanical thrombectomy for acute ischemic stroke: final results of the multi MERCI trial. Stroke. 2008;39:1205-1212.

86. Smith WS, Sung G, Starkman S, et al. Safety and efficacy of mechanical embolectomy in acute ischemic stroke: results of the MERCI trial. Stroke. 2005;36:1432-1438.

87. Furie KL, Kasner SE, Adams RJ, et al. Guidelines for the prevention of stroke in patients with stroke or transient ischemic attack. A guideline for healthcare professionals from the American Heart Association/ American Stroke Association. Stroke. 2011;42:227-276.

88. von Kummer R, Gerber J. IMS-3, synthesis, and MR rescue: no disaster, but down to earth. Clin Neuroradiol. 2013;23:1-3.

89. Arboix A, Garcia-Eroles L, Oliveres M, Targa C, Balcells M, Massons J. Pretreatment with statins improves early outcome in patients with firstever ischemic stroke: pleiotropic effect of statins or a beneficial effect of hypercholesterolemia? BMC Neurol. 2010;10:47.

90. Molina CA, Chamorro A, Rovira A, et al. REVASCAT: a randomized trial of revascularization with SOLITAIRE FR ${ }^{\circledR}$ device vs best medical therapy in the treatment of acute stroke due to anterior circulation large vessel occlusion presenting within eight-hours of symptom onset. Int $J$ Stroke. 2013; doi:10.1111/ijs.12157.

91. Furie KL, Goldstein LB, Albers GW, et al. Oral antithrombotic agents for the prevention of stroke in nonvalvular atrial fibrillation. A Science Advisory for Healthcare Professionals From the American Heart Association/American Stroke Association. Stroke. 2012;43: 3442-3453.

92. Guia de Diagnòstic i tractament de les Malalties Vasculars Cerebrals. En: Guies Mèdiques oficials de diagnòstic i tractament. 2nd ed. Barcelona: Societat Catalana de Neurologia; 2011.
93. Andersen KK, Andersen ZJ, Olsen TS. Age- and gender-specific prevalence of cardiovascular risk factors in 40,102 patients with firstever ischemic stroke: a Nationwide Danish Study. Stroke. 2010;41: 2768-2774.

94. Camm AJ, Lip GY, De Caterina R, et al. 2012 focused update of the ESC Guidelines for the management of atrial fibrillation: an update of the 2010 ESC Guidelines for the management of atrial fibrillation. Developed with the special contribution of the European Heart Rhythm Association. Eur Heart J. 2012;33:2719-2747.

95. Cairns JA, Connolly S, McMurtry S, Stephenson M, Talajic M. Canadian Cardiovascular Society atrial fibrillation guidelines 2010: prevention of stroke and systemic thromboembolism in atrial fibrillation and flutter. Can J Cardiol. 2011;27(1):74-90.

96. Culeras A, Messé SR, Chaturvedi S, Kase CS, Gronseth G. Summary of evidence-based guideline update: prevention of stroke in nonvalvular atrial fibrillation. Report of the Guideline Subcommittee of the American Academy of Neurology. Neurology. 2014;82(8): 716-724.

97. Baron TH, Kamath PS, McBane RD. Management of antithrombotic therapy in patients undergoing invasive procedures. $N$ Engl $J$ Med. 2013;368(22):2113-2124.

98. The European Stroke Organisation (ESO) Executive Committee and the ESO Writing Committee. Guidelines for management of ischemic stroke and transient ischemic attack 2008. Cerebrovasc Dis. 2008;25(5):457-507.

99. Font MA, Arboix A, Krupinski J. Angiogenesis, neurogenesis and neuroplasticity in ischemic stroke. Curr Cardiol Rev. 2010;6(3): 238-244.

100. Lubitz SA, Yi BA, Ellinor PT. Genetics of atrial fibrillation. Heart Fail Clin. 2010;6(2):239-247.

101. Luo M, Li J, Lai R, et al. Varainet rs 1906591 on chromosome 4q25 confers increased risk of cardioembolic stroke in Chinese patents. J Clin Neurosci. 2014;21(10):1740-1743.

102. Traylor M, Farrall M, Holliday EG, et al. Genetic risk factors for ischaemic stroke and its subtypes (the METASTROKE collaboration): a meta-analysis of genome-wide association studies. Lancet Neurol. 2012;11(11):951-962.

103. Santamarina E, Penalba A, García-Berrocoso T, et al. Biomarker level improves the diagnosis of embolia source in ischemic stroke of unknown origin. J Neurol. 2012;259(12):2538-2545.
Research Reports in Clinical Cardiology

\section{Publish your work in this journal}

Research Reports in Clinical Cardiology is an international, peerreviewed, open access journal publishing original research, reports, editorials, reviews and commentaries on all areas of cardiology in the clinic and laboratory. The manuscript management system is completely online and includes a very quick and fair peer-review system.

\section{Dovepress}

Visit http://www.dovepress.com/testimonials.php to read real quotes from published authors. 